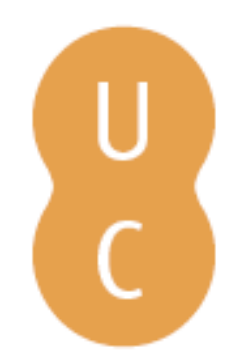

\title{
nombalina
}

\section{Poesia e feminismo: nota à margem de um poema de Carolyn Creedon}

\author{
Autor(es): $\quad$ Moisés, Carlos Felipe
}

Publicado por: Imprensa da Universidade de Coimbra

URL

persistente: URI:http://hdl.handle.net/10316.2/42351

DOI: $\quad$ DOI:https://doi.org./10.14195/978-989-26-1308-6_39

Accessed : $\quad$ 26-Apr-2023 15:58:10

A navegação consulta e descarregamento dos títulos inseridos nas Bibliotecas Digitais UC Digitalis, UC Pombalina e UC Impactum, pressupõem a aceitação plena e sem reservas dos Termos e Condições de Uso destas Bibliotecas Digitais, disponíveis em https://digitalis.uc.pt/pt-pt/termos.

Conforme exposto nos referidos Termos e Condições de Uso, o descarregamento de títulos de acesso restrito requer uma licença válida de autorização devendo o utilizador aceder ao(s) documento(s) a partir de um endereço de IP da instituição detentora da supramencionada licença.

Ao utilizador é apenas permitido o descarregamento para uso pessoal, pelo que o emprego do(s) título(s) descarregado(s) para outro fim, designadamente comercial, carece de autorização do respetivo autor ou editor da obra.

Na medida em que todas as obras da UC Digitalis se encontram protegidas pelo Código do Direito de Autor e Direitos Conexos e demais legislação aplicável, toda a cópia, parcial ou total, deste documento, nos casos em que é legalmente admitida, deverá conter ou fazer-se acompanhar por este aviso.

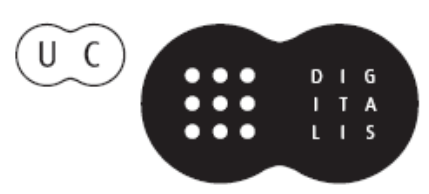





\section{POESIA E FEMINISMO \\ NOTA À MARGEM DE UM POEMA \\ DECAROLYNCREEDON}

Carlos Felipe Moisés

Resumo: A poesia de Carolyn Creedon tem sido elogiada basicamente em razão da franqueza com que trata de temas e motivos extraídos da vida cotidiana. "Litania", um dos seus mais belos poemas, é um bom exemplo, já que descreve com singeleza a sua experiência como garçonete. Mas seu notável domínio da linguagem poética sugere que reconsideremos a tradicional dicotomia que opõe "eu lírico" a "eu biográfico", ou ser a parecer.

Resumo: Sinceridade; fingimento; linguagem poética; eu lírico; eu biográfico.

Abstract: Carolyn Creedon's poetry has been acclaimed mainly for her frankness in dealing with themes and motifs of daily life. "Litany", one of her most beautiful poems, is a good example, once it candidly describes her experience as a waitress. But Creedon's rare command of poetic language suggests that we should reconsider the traditional dichotomy 
between the "lyrical I" and the "biographical I", or between being and making believe.

Keywords: Sincerity; pretending; poetic language; lyrical I; biographical I.

Carolyn Creedon nasceu em Newport News, Virginia, em 1969. Ainda muito jovem, deixou a cidade natal e andou por várias partes, sempre nos Estados Unidos, até se fixar, no final dos anos 80, em San Francisco, onde viveu por um bom tempo, trabalhando como garçonete. Data dessa época sua descoberta da poesia. Na altura, ela assim o descreveu:

Sou basicamente uma garçonete que vai à escola. Eu nunca tinha escrito um poema antes de frequentar uma oficina de poesia, dois anos atrás. Meu professor me mostrou como explorar os detalhes; por isso tento dizer o máximo que posso em cada linha. Eu sabia que gostava de lidar com as palavras, tanto pelo seu derramado ou sua secura, e pela sua sonoridade, como pelo seu significado.

Um dos primeiros poemas que escreveu intitula-se "Litany" (Litania) e parece ter brotado diretamente da sua experiência como garçonete, animada pelo "derramado ou pela secura" das palavras. Com esse poema, ela conquistou vários prêmios em festivais regionais e teve a alegria de vê-lo acolhido, em 1993, pela prestigiosa revista American Poetry Review. E este foi só o primeiro passo.

Desde 1988, uma grande editora de New York vinha lançando uma série de antologias, de periodicidade anual, sob o título The Best of American Poetry, cada volume confiado a um poeta de pres- 
tígio, que então escolhia 75 poemas, dentre os publicados naquele ano, nos principais jornais e revistas do país. "Litania" comparece na coletânea correspondente a 1993, da responsabilidade de Louise Glück. Saído o décimo volume da série, a editora anuncia para o ano seguinte a antologia das antologias, isto é, os melhores 75 poemas dentre os 750 reunidos na década que findava. Harold Bloom foi o nome escolhido para selecionar o melhor do melhor da poesia norte-americana publicada entre 1988 e $1997 .{ }^{1} \mathrm{E}$ ali está, mais uma vez, "Litania": Creedon ao lado de Ashbery, Ginsberg, Simic e tantos outros expoentes da moderna poesia do seu país.

Nessa altura, Creedon já havia deixado para trás os bares e restaurantes de San Francisco ("Sou uma veterana de guerra, quinze anos na guerra das garçonetes", ela dirá, anos mais tarde), para voltar a estudar, primeiro na Universidade de Washington (M.A.), depois na Universidade de Virginia (M.F.A.). Mas não deixou a poesia. Embora experimentasse períodos de desconsolo e esterilidade, ${ }^{2}$ continuou a escrever e a ganhar prêmios, como o Academy of American Poets, o Alehouse Happy Hour Poetry e o Stan and Wick Poetry. Este último lhe rendeu a estreia em livro, Wet (Úmido).

Vários críticos se manifestaram a respeito. Eleanor Wilner, por exemplo, chama a atenção para sua poderosa linguagem, que "se move com fluida energia, velocidade emocional de tirar o fôlego e notável destreza formal, eletrificada de humor, alimentada pela raiva, cadência após cadência"; ${ }^{3}$ Ellen Doré Watson assevera que,

1 The Best of the Best American Poetry, New York, Simon \& Schuster, 1998, prefácio de David Lehman, introdução de Harold Bloom. O poema "Litany" ocupa as páginas $88-90$ e a edição conta ainda com um saboroso depoimento da autora (309-310), do qual transcrevemos, mais acima, o trecho inicial.

2 Em mensagem pessoal, datada de 19 de agosto de 2006, ela se queixava: "Você sabe, eu tive o coração partido e parei de escrever poesia por treze anos, para trabalhar em restaurantes como garçonete".

${ }^{3}$ Esta e as restantes apreciações citadas neste parágrafo figuram na contracapa de Wet. ed.cit. 
"sempre desassombrado, Wet é também imbuído de largos lances de ansiedade e de pungente ternura. Seja gotejando, seja em esguichos de catarata, essa nova e surpreendente voz não deixa nada para trás"; segundo Edward Hirsch, julgador do Wick Poetry Prize, "há um inusitado sentimento religioso que insiste em irromper nessas páginas", possível razão para que ele confesse: "é de coração aberto que dou as boas vindas a esse ardente e flamejante livro". O mesmo Hirsch afirma também que se deixou comover "pela maneira como Carolyn Creedon trata a experiência como se fosse sagrada. Ela não se detém diante das verdades mais duras e expressa com franqueza suas frustações, suas ansiedades, seus infortúnios". No mesmo rumo, Wilner vai além: esses poemas "nos desafiam a separar o sagrado do profano, os mitos da banalidade cotidiana, o intelecto dos instintos". Todos parecem empenhados em demonstrar que ninguém é indiferente aos poemas de Creedon. Mas nenhum é tão enfático quanto Bloom: "ela é única, ninguém se assemelha a ela, entre os que hoje escrevem em nosso país. Sua assertividade e seu imediatismo fazem dela uma legítima neta do sublime Walt Whitman".

Neta de Walt Whitman? Ninguém escreve como ela? Velocidade emocional de tirar o fôlego? Vazamentos e jorros de catarata? Um livro espantoso, inflamado e ardente? Essa tem sido a atmosfera criada, já antes do primeiro livro, em torno da poesia de Creedon. David Lehman, no prefácio à grande antologia organizada por Bloom, de certo modo já o previra, embora não se referisse especificamente à garçonete-poeta. De acordo com seu editor, a referida antologia "ultrapassará as diferenças sectárias e os conflitos tribais ...; poemas de tradições rivais vão-se irmanar, em benefício mútuo". E Lehman prevê: "Leitores famintos de poesia responderão com ardor" (9) ${ }^{4}$.

\footnotetext{
${ }^{4}$ Citações subsequentes incluídas em Lehman, The Best of the Best American Poetry, serão identificada pelas iniciais $B P A$.
} 
A atmosfera sugerida pelos comentários a Wet (todos responderam com ardor, como previra Lehman) mimetiza o fulgor que parece brotar, naturalmente, dos versos de Creedon. Com ou sem exagero, o ardor e o entusiasmo se justificam. Difícil imaginar que Bloom, Wilner, Watson, Hirsch e os demais tenham decidido, de comum acordo, pôr de lado o tradicional comedimento do crítico e alardear seu secreto pendor para a exaltação emocional e a abundância de metáforas. "Litany" (Creedon 8-9) é um bom exemplo de como essa poesia pode induzir o leitor a se exaltar, qualquer que seja o sentido que atribua, o literal e o não-literal, às metáforas. Vamos ao poema famoso: ${ }^{5}$

\section{Litania}

Tom, você me deixa amar você no seu restaurante?

Eu deixo você preparar para mim um sanduíche da sua invenção,

[que depois eu como e batizo

carolyn sandwich. Então você beija meus lábios e sente o gosto

[da maionese e

é assim que você vai me amar no meu restaurante.

Tom, você pode vir ao meu apartamento bege, vazio, me ajudar a

[consertar o sofá-cama?

Sim, e eu deixo os parafusos meio frouxos, aí quando a gente se deitar [nele, mais tarde,

ele balança feito um berço e então você fica sabendo quem é meu bebê.

${ }^{5}$ Fiz o possível para que os versos tivessem em português a mesma naturalidade do original. Mas tive de optar, claro está, pela modalidade de português que me é mais familiar, a brasileira. Para o leitor português, por exemplo, várias das soluções a que recorri não serão tão naturais assim. 
Tom, eu estou sentada na minha bicicleta suja, na varanda. Você vem [da cozinha olhar as pessoas comigo?

Sim, e depois a gente aposta corrida até o seu quarto. Eu ganho e a [gente se emaranha no seu acolchoado enquanto o suor escorre de nossas barrigas e de [nossas testas.

Tom, as estrelas estão quietas esta noite como pedrinhas de bala de [goma na caixa de joias de uma menininha. Mais tarde a gente pode caminhar até o lago [dos patos?

Sim, e a gente pode até pegar o caminho mais longo até o parquinho.

[Eu empurro você na balança, mas prometa que você vai-se agarrar firme. Se você cair [eu posso desaparecer.

Tom, nós podemos fazer um nenê, juntos? Eu quero ser uma grávida [bem grandona, com uma cara de mulher bem amada, e dar a você uma irrequieta filha ruivinha. Não, mas eu gozo dentro de você e você vai ser minha filha.

Tom, você passa a noite comigo e dorme tão grudado que a gente vira [uma só pessoa? Não, mas eu vou deitar nos seus lençóis e saborear você. Vão ficar penas de você na minha língua e então eu nunca vou me esquecer de você.

Tom, quando a gente estiver na fila do caixa no mercadinho posso pôr [minhas mãos nos seus bolsos de trás e meus lábios e meu nariz na sua camiseta e sentir [a saliência de lâmina do seu ombro? 
Não, mas depois você pode se deitar em mim e me tocar de leve e

[quando eu for embora posso

deixar minha camiseta para você usar de pijama e assim a noite toda

[você fica apertada

contra o seu pensamento em mim

Tom, se eu chorar e quiser esperar até que você precise de mim você

[promete que um dia

vai precisar de mim?

Não, mas eu fico sentado em silêncio enquanto você se enfurece, você

[pode derrubar as cadeiras

montanha abaixo. Eu vou ser sempre o mesmo e você vai esperar,

[sempre.

Tom, você trepa bem no alto do lixão e rouba o sol para mim? Ele está lá pendurado e eu quero ele.

Não, vai queimar meus dedos. Ninguém pode ter o sol: ele é emprestado [por Deus.

Mas eu faço um desenho e mando para você de Richmond e então você alisa bem o papel e fica com um pedaço de mim e o sol também

Tom, está tão quente aqui, eu acho que estou nascendo. Você pode voltar de Richmond e me batizar com sexo e água fresca?

Eu vou voltar de Richmond. Vou afastar o seu cabelo úmido e fino de trás do seu pescoço e vou lamber o sal da sua nuca. Depois vou embora.

Tom, Richmond é tão longe. Como vou saber quanto você me ama?

Eu deixei você. É assim que você vai saber.

Creedon parece falar em seu próprio nome. No mesmo depoimento antes citado, ela o confirma: “'Litania', para mim, é um poema-súmula. Aconteceu de um jorro, cerca de uma semana depois que 
meu amante, finalmente, tinha me abandonado. As palavras foram se derramando, num dia especialmente úmido de agosto; eu não tinha ar condicionado e estava inteiramente só, com meu lenço colorido e meu traje de banho. Eu ansiava por uma proximidade coberta de suor; pelo menos pude senti-la ao dar à luz esse poema" (Lehman 309). Muitos leitores passarão ao largo do que parece ser uma evidência (a "veracidade" da situação aí descrita) e só lhe atribuirão a importância indevida. Os mais atentos, porém, sentirão o embaraço que resulta da confusão entre os polos bem comportados a que nos habituamos desde a metade do século passado: aqui o eu-lírico, ali o eu-biográfico, vistos como realidades independentes e incomunicáveis. Ao longo de décadas, leitores e críticos apegaram-se à prestimosa dicotomia que proibia frases como "Eliot diz", "Auden pensa", "Ashbery deseja” etc., pois quem "diz", "pensa” ou "deseja”, no poema, não é o cidadão que o escreveu, mas sim. . . o "eu-lírico". Se tomássemos um pelo outro, cometeríamos o pecado capital da "falácia biográfica". Pois Carolyn Creedon ousa desalojar-nos da cômoda separação. Para lidar com "Litania", não basta aludir, aristotelicamente, à sua eventual verossimilhança: é preciso enfrentar, ao mesmo tempo, a verdade biográfica aí exposta. Ora, se estamos diante de algo verdadeiro, isso basta: por que havemos de nos preocupar com o verossimil?

Para os "estudos culturais", porém, esse é um falso problema, meramente "literário". O que importa no poema, segundo a visão culturalista, é que aí temos a voz de uma pobre e indefesa garçonete, vítima do machismo dominante. Ferrenho inimigo do culturalismo, Bloom fustiga esses "inimigos da estética, empenhados em nos subjugar. Isso é de uma distorção inacreditável, pois só faz obedecer ao critério hoje em vigor: o que mais interessa, ao candidato a poeta, é a raça, o gênero, a orientação sexual, a origem étnica e o propósito político" (idem 16). Mais adiante, o crítico radicaliza: "A autêntica poesia americana é necessariamente difícil; é a nossa arte elitista, 
embora essa elite não tenha nada a ver com classe social, gênero, preferências eróticas, traços étnicos, raça ou sectarismo" (idem 19). E conclui: "Divulgar, enaltecer e ensinar maus poemas em nome das causas mais nobres é simplesmente destrutivo para essas mesmas causas" (idem 20).

Os adversários de Bloom alegariam que "Litania" descreve situações de vida efetivamente vividas pela cidadã Carolyn Creedon; logo, podemos tomá-lo ao pé da letra, com a certeza de que esta será a atitude politicamente correta. Não assim para o crítico, cuja escolha não se deveu ao gênero nem à condição social da autora, mas à qualidade estético-literária do poema. A julgar pelos critérios que expõe na introdução da antologia que organizou, Bloom valoriza acima de tudo a sabedoria com que Creedon recorta os versos, quase sempre na contramão da ordenação sintática, e joga com os "gushes and droughts" das palavras, no encalço da mais rica e aliciante sonoridade, ao mesmo tempo em que espalha, ao longo do percurso, suas inusitadas associações: o gosto de maionese no sanduíche, o conserto do sofá-cama, a bicicleta suja, a caixa de joias da menininha, o balanço, a grávida grandona, o mercadinho, o lixão, o desenho do sol. . .

Com transcendente (involuntária?) ironia, Creedon desloca, do drama existencial da garçonete para a arte da escrita, o foco substancial do seu poema, cumprindo, aliás, com a espécie de "programa" que ela assim descreve: "Eu acho que tento escrever poemas do jeito como eu penso, e eu 'penso' um poema em longas linhas conectadas por uma porção de 'ands' e 'ifs'. . . Os finais de sentenças, e outras pausas, só aparecem quando eu me sinto carente de tempo e de esperança" (Lehman 309). Eleanor Wilner observa, com agudeza, que os poemas de Creedon "nos desafiam a separar o sagrado do profano, os mitos da banalidade cotidiana, o intelecto dos instintos" 6 ,

6 V. nota 2. 
e poucos resistem. O desafio maior, porém, consistiria em conviver com a ideia de que esses e outros pares de opostos são inseparáveis, como singelamente demonstra essa inquietante poesia. Mas, neste caso, como ficariam os bem delimitados escaninhos em que nos habituamos a alojar a incontornável hibridez da condição humana?

E "Litania" nos induz a insistir na desgastada separação entre eu-lírico e eu-biográfico, não para repô-la em circulação, mas para encará-la de outro ângulo. O eu único, aí representado, talvez não seja, para decepção dos culturalistas, o biográfico, mas o da ficção criada pelo poder encantatório das palavras. Digamo-lo com simplicidade (a simplicidade à qual acedemos depois que alguém foi capaz de aliviá-la da complexidade): Carolyn Creedon "chega a fingir que é dor / A dor que deveras sente". ${ }^{7}$ Ao chamar a atenção para a guerra das garçonetes, miseravelmente exploradas pelo machismo empedernido, ela nos distrai e disfarça o superior "fingimento" de que é capaz e que lhe confere toda a dignidade possível.

"Litania", sim: ladainha, oração. . . O título é apropriado. Mas talvez coubesse um subtítulo: "cantiga d'amor-d'amigo". Tantos séculos depois, a mulher-poeta por fim se vinga do machismo avant la lettre perpetrado por nossos prepotentes trovadores, que julgavam saber de tudo o que dissesse respeito à coita amorosa, de homens e de mulheres. Creedon fala por si e pelo outro, pela mulher que é e pelo homem à sua mercê. Por isso, tal como acontece à menina que no século XIII se queixava: "ai flores, ai flores do verde pino", esse Tom que afrouxa os parafusos do sofá-cama, lambe o suor da nuca da garçonete e receia queimar os dedos, talvez também não saiba ler e escrever, razão pela qual precisa, para existir, que a mulher lhe dê voz. Neta do sublime Whitman, como quer Bloom? Quem sabe. . Mas, se assim é, por que não, também, tatara-tataraneta

\footnotetext{
${ }^{7}$ Fernando Pessoa, "Autopsicografia", in Poesia do Eu, Obra essencial de Fernando Pessoa, vol. 2, edição Richard Zenith, Lisboa, Assírio \& Alvim, 2006, p. 241.
} 
(bastarda) de D. Dinis, sobrinha de Fernando Pessoa, afilhada de Álvaro de Campos ou de Almada Negreiros?

Afinal, poesia feminina? Feminista, antifeminista? Poesia politicamente correta? Incorretíssima? A Carolyn Creedon talvez não desagrade verificar que seus versos são um potente foco gerador de intermináveis polêmicas. Confesso que teria curiosidade em saber o que pensa, hoje, a autora a respeito do seu "Litany", ao qual tantos leitores reagiram "com ardor". Em 2006 trocamos mensagens, mas acabamos por perder contato, no instante em que ela tomava a decisão de concluir o seu mestrado (numa universidade próxima da sua cidade natal), e preparava-se para publicar o primeiro livro. Creedon vive hoje em Charlottesville, coordena oficinas de criação literária e - esperamos todos - continua a escrever sua admirável poesia.

\section{Obras citadas}

Creedon, Carolyn. Wet: Poems. Kent, Ohio, The Kent State University Press, 2012. Print.

Lehman, David. The Best of the Best American Poetry. Introd. Harold Bloom. New York, Simon \& Schuster, 1998. Print. 